\title{
The Effect of Size on the Distortion Behavior After Carburisation and Quenching Processes of Gears
}

Koen Decroos ${ }^{1,2, *}$ and Marc Seefeldt ${ }^{3}$

${ }^{1}$ Opti Quench, 9000 Gent, Belgium

${ }^{2}$ University of Gent, Faculty of Engineering, Department of Metallurgy and Materials Science, 9000 Gent, Belgium

${ }^{3}$ Catholic University of Leuven, Faculty of Engineering, Department of Metallurgy and Materials Engineering, 3001 Heverlee (Leuven), Belgium

\begin{abstract}
The carbon concentration distribution, temperature history, phase compositions, stresses, and deformations as a consequence of a carburization and oil quenching process, can be modelled by a diffusion Finite Element model followed by a coupled thermo-metallo-mechanical Finite Element model. The aim of current research is to investigate the effect of size of the component on the final distortion behaviour. Therefore the same carburization and quenching processes have been modelled for identical gear components consisting of the same material, and the same geometry but with a length scales differing with a factor 10. The two models incorporate gravity and Transformation Induced Plasticity. The results show a very similar carbon penetration from the outer surface, higher cooling rates in the smaller gear, a higher martensite concentration in the smaller gear, similar distributions and magnitude of residual stresses, but a completely different deformation behaviour.
\end{abstract} Publication History:

Received: November 25, 2017 Accepted: December 27, 2017

Published: December 29, 2017

Keywords:

Graphene, Ambipolar barrister, Built-in electric field, Tunable work function

\section{Introduction}

Because of the operating conditions, a gear's contact surface should be hard in order to be resistant to the contact wear and deformation, whereas the inner core needs to be tough in order to be resistant to crack propagation [1]. When placing a gear in a carbon-rich environment (carburizing) at high temperature in the austenitic range where carbon can diffuse into the steel, followed by rapid cooling or quenching in a quenchant (for example an oil), a zone close to the external surface undergoes a transformation to martensite. Further away from the surface the material does not undergo such a drastic cooling and has a lower carbon concentration, the austenite transforms to bainite, pearlite and ferrite.

During and after the carburization process followed by a heat treatment, because of inhomogeneous plastic deformations, the quenched specimen gets inevitably distorted [2]. These deformations are detrimental for the lifetime in operation of the gear, since higher deviations from the desired shape lead to higher out-of-balance forces. In large gears, corrective actions by means of material removal can be required. The most common way to deal with the distortions is by material removal after the quenching process. Since it is necessary for the gear to have a certain carbon penetration depth, one anticipates on the material removal by over dimensioning the carbon penetration in the carburization process. This is an expensive process since high temperatures and long times are involved [2]. Therefore, detailed knowledge of the heat treatment and the involved deformations is important.

In the case of large component gears, empirical methods (trial and error) are expensive because of the high material cost, and the complex testing strategy due to the numerous parameters that can influence the final result $[3,4]$. The aim of the current research is to investigate to what extent experimental tests on similarly shaped specimens on laboratory scale can be used to predict the deformations on real component scale, in terms of nature and magnitude. Therefore, 2 simulations have been done. They both investigate the same processes with similar times and temperatures, and the same material, but with different sizes. The first specimen has the real time geometry, whereas the lab-scale specimen has the real time geometry scaled with a factor 10 .
The ability to deal with complex geometries and nonlinear material behavior makes the Finite Element (FE) method a suitable modeling technique for these kind of problems. Moreover, commercial FE software packages like ANSYS are compatible with CAD software [5]. Previous studies investigated stress and deformation development by coupling thermal, metallurgical, and mechanical fields for simplified geometries [6,7], or small samples [8]. Current research focusses on both large and small gears and includes effects that are typical for the 3 dimensional larger problems, like the gravitational effects, and the gear's immersion time in the quenching bath. Decroos et al. showed how these effects, as well as the Transformation Induced Plasticity (TRIP) strain can be included in a commercial Finite Element software [9].

\section{Specimen and Process}

The real gear component under consideration is an involute gear with 48 teeth, an inner diameter of $70 \mathrm{~cm}$, a root diameter of $100 \mathrm{~cm}$, and a height of $30 \mathrm{~cm}$. A two-dimensional cross section of a tooth is shown in Figure 1.

The total mass that has to be carried by 48 chains fixed at the gear is approximately $4100 \mathrm{~kg}$. The chains are attached to the gear at hanging points located on the top surface in a symmetry plane of a tooth at one third from the root and two third from the inner diameter. The lab-scale specimen has exactly the same shape, but with all lengths 10 times as small as the real-time specimen. This means that there also 48 teeth, the inner diameter is $7 \mathrm{~cm}$, the root diameter $10 \mathrm{~cm}$, and the height $3 \mathrm{~cm}$. The total mass is approximately $4.1 \mathrm{~kg}$.

In a carburization process, the material which is ferritic at room temperature, is heated in the austenitic stage and brought in a carbon ${ }^{\overline{ }}$ Corresponding Author: Prof. Koen Decroos, University of Gent, Faculty of Engineering, Department of Metallurgy and Materials Science, 9000 Gent, Belgium, Tel: +32 16321274; E-mail: koenraad.decroos@mtm.kuleuven.be

Citation: Decroos K, Seefeldt M (2017) The Effect of Size on the Distortion Behavior After Carburisation and Quenching Processes of Gears. Int J Metall Mater Eng 3: 139. doi: https://doi.org/10.15344/2455-2372/2017/139

Copyright: (C) 2017 Decroos, et al. This is an open-access article distributed under the terms of the Creative Commons Attribution License, which permits unrestricted use, distribution, and reproduction in any medium, provided the original author and source are credited. 
Citation: Decroos K, Seefeldt M (2017) The Effect of Size on the Distortion Behavior After Carburisation and Quenching Processes of Gears. Int J Metall Mater Eng 3: 139. doi: https://doi.org/10.15344/2455-2372/2017/139

Page 2 of 10

rich gas environment, in order to promote carbon diffusioni into the material. After carburization the material is soaked [2], i.e.is hold on a slightly lower temperature, to allow further diffusion of carbon into the material. After soaking, the gear is quenched by immersing into an oil bath. Then the material is hold at a temperature around $150^{\circ} \mathrm{C}$ to decrease the brittleness of the martensite without significant loss of hardness. This process is called tempering. The time/temperature history of the carburization and heat treatment process is schematically shown in Figure 2.

In the current process, the specimen is held for 10 hours at $950^{\circ} \mathrm{C}$ in a carbon-rich environment, is then soaked at a temperature of $920^{\circ} \mathrm{C}$, and afterwards quenched in an oil bath of $90^{\circ} \mathrm{C}$ for 2 hours, followed by tempering at $150^{\circ} \mathrm{C}$ during 2 hours, and followed by 20 hours of air cooling.

The gear material is a case hardening steel, which means that is an acceptably soft steel with a high ability to form martensite upon quenching [10]. The alloying elements are $\mathrm{Ni}$ (1.8 wt\%), $\mathrm{Cr}(1.08 \mathrm{wt} \%)$, Mn (0.9 wt\%), and Mo (0.18 wt\%). The initial carbon concentration is $0.19 \mathrm{wt} \%$.

\section{Numerical Procedure}

\section{Modeling the physical phenomena}

\section{Field problems and their couplings}

The physical phenomena and their couplings that are present in a carburization and quenching process shown in Figure 2 are shown in Figure 3.

For every point of the specimen and throughout the whole process, the diffusion model solves the carbon concentration problem, the thermal model calculates the temperature, the metallurgical model the phase composition in terms of the volume fraction for each phase, and the mechanical model the stresses, strains, and displacements. The carbon concentrations are an input for a coupled thermometallo-mechanical model since they determine both the thermal and mechanical material properties as well as the transformation kinetics of the metallographic model. As shortly explained in Figure 3 , the phase compositions, temperatures and temperature rates, and the strains and stresses each influence each other. More details can be found in reference [2].

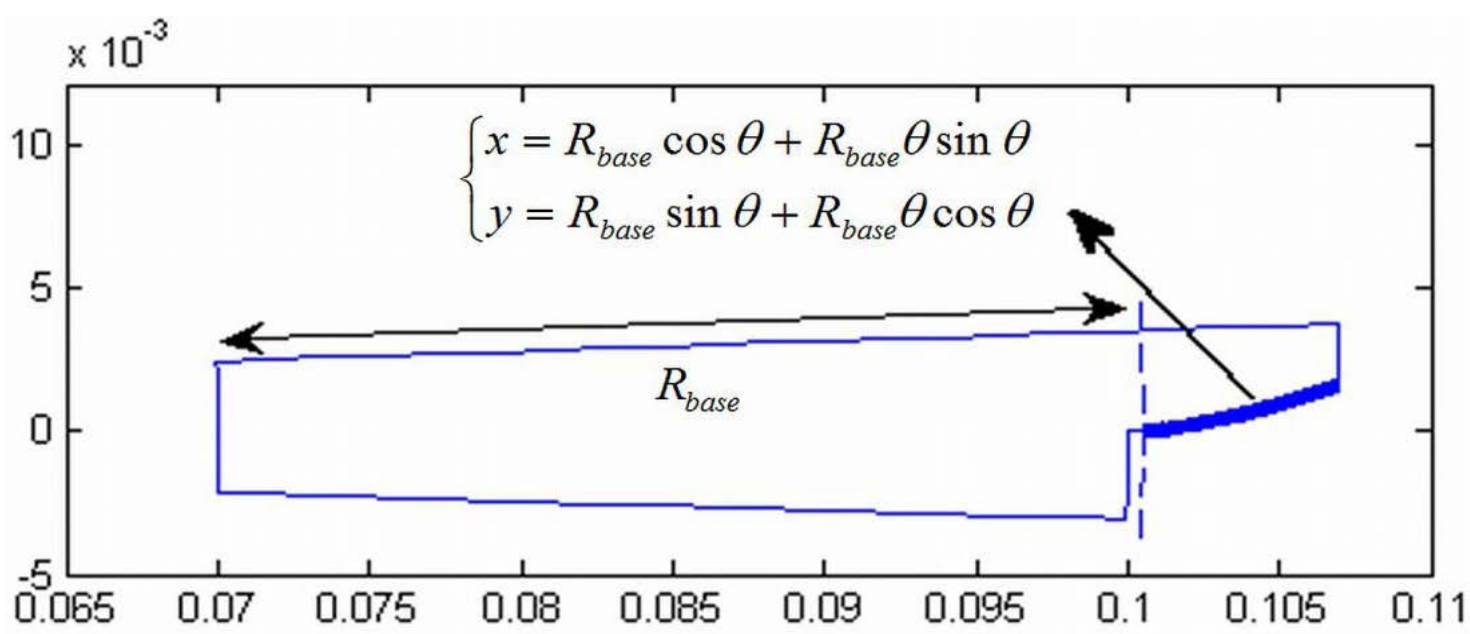

Figure 1: Geometry of the gear used for input in the Finite Element model. For the small gear, length units are in $\mathrm{m}$, for the large gear, length units are in $10 \mathrm{~m}$. The parametric equation of the involute tooth line is shown and is valid for both cases.

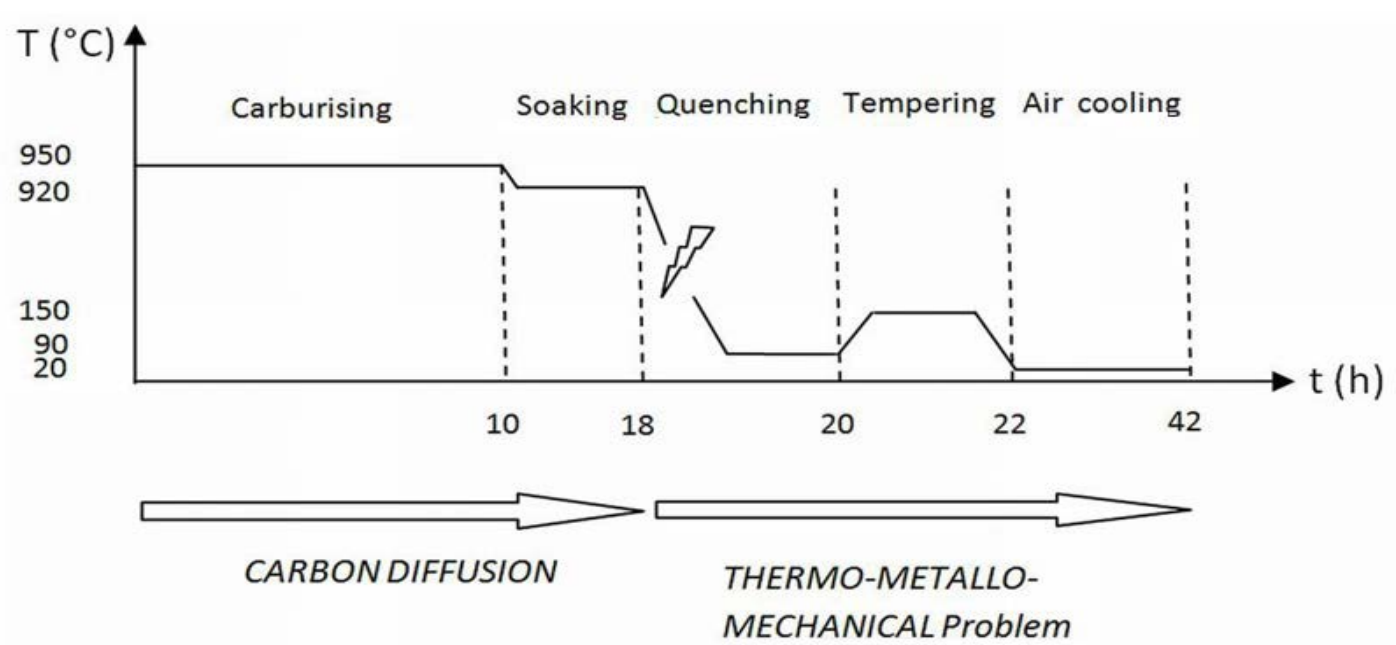

Figure 2: Schematic representation of the time/temperature history of the carburization and heat treatment process. 
Citation: Decroos K, Seefeldt M (2017) The Effect of Size on the Distortion Behavior After Carburisation and Quenching Processes of Gears. Int J Metall Mater Eng 3: 139. doi: https://doi.org/10.15344/2455-2372/2017/139

Page 3 of 10

\section{Diffusion model}

In the absence of body carbon generation sources, Fick's law describes the evolution of the carbon concentration $c(x, y, z, t)[1]$.

$$
\frac{\partial c}{\partial t}-D \underline{\nabla}^{2} c=0
$$

Hereby $\mathrm{D}$ is the diffusion coefficient, which is temperature dependent, but assumed to be independent of the carbon concentration.

The boundary condition on the surface layer determines to which extent carbon is transferred into the material, and is dependent on the carbon transfer coefficient $h_{c}$, and the carbon potential $C_{0}[2]$, as shown in equation 2 . The vector $\underline{n}$ denotes the normal on the external surface.

\section{Thermal mode}

$$
D \underline{\nabla} c . \underline{n}=h_{c}\left(C_{0}-c\right)
$$

A solution of a thermal analysis has to satisfy two basic laws, namely the conservation of energy and Fourier's law of heat flow, which results in the heat equation 3 .

$$
j=\rho C_{v} \frac{\partial T}{\partial t}-k \underline{\nabla}^{2} T
$$

Hereby $\mathrm{T}$ is the temperature $(\mathrm{K}), \mathrm{k}$ the isotropic heat conduction coefficient $(\mathrm{W} / \mathrm{m}), \rho$ the density $\left(\mathrm{kg} / \mathrm{m}^{3}\right)$, and $\mathrm{C}_{\mathrm{v}}$ the heat capacity at constant volume, $\mathrm{j}$ a heat generation rate per unit of volume.

In a quenching process, there are no thermal heat sources, although during phase transformations the latent heat of transformation can be considered as a body heat source. If phase $\mathrm{i}$ transforms into a phase $\mathrm{j}$ with a volume fraction transformation rate of $\dot{f}_{i \rightarrow j}$, the heat generated per unit of volume is given by:

$$
j=\dot{f}_{i \rightarrow j} \Delta H_{i \rightarrow j}
$$

Hereby $\Delta H_{i \rightarrow j}$ is the latent heat per unit of volume for the transformation from phase $i$ to phase $j$.

Convection heat losses are described by the convective heat flux on the external surface boundary as given in equation 5 .

$$
q_{n}=-k \underline{\nabla} T \cdot \underline{n}=h(T)\left(T-T_{r e f}\right)
$$

Hereby $\mathrm{h}$ is the convective heat transfer coefficient $\underline{n}$ the external normal on the surface, $\mathrm{T}$ the surface temperature, and $\mathrm{T}_{\text {ref }}$ the ambient temperature.

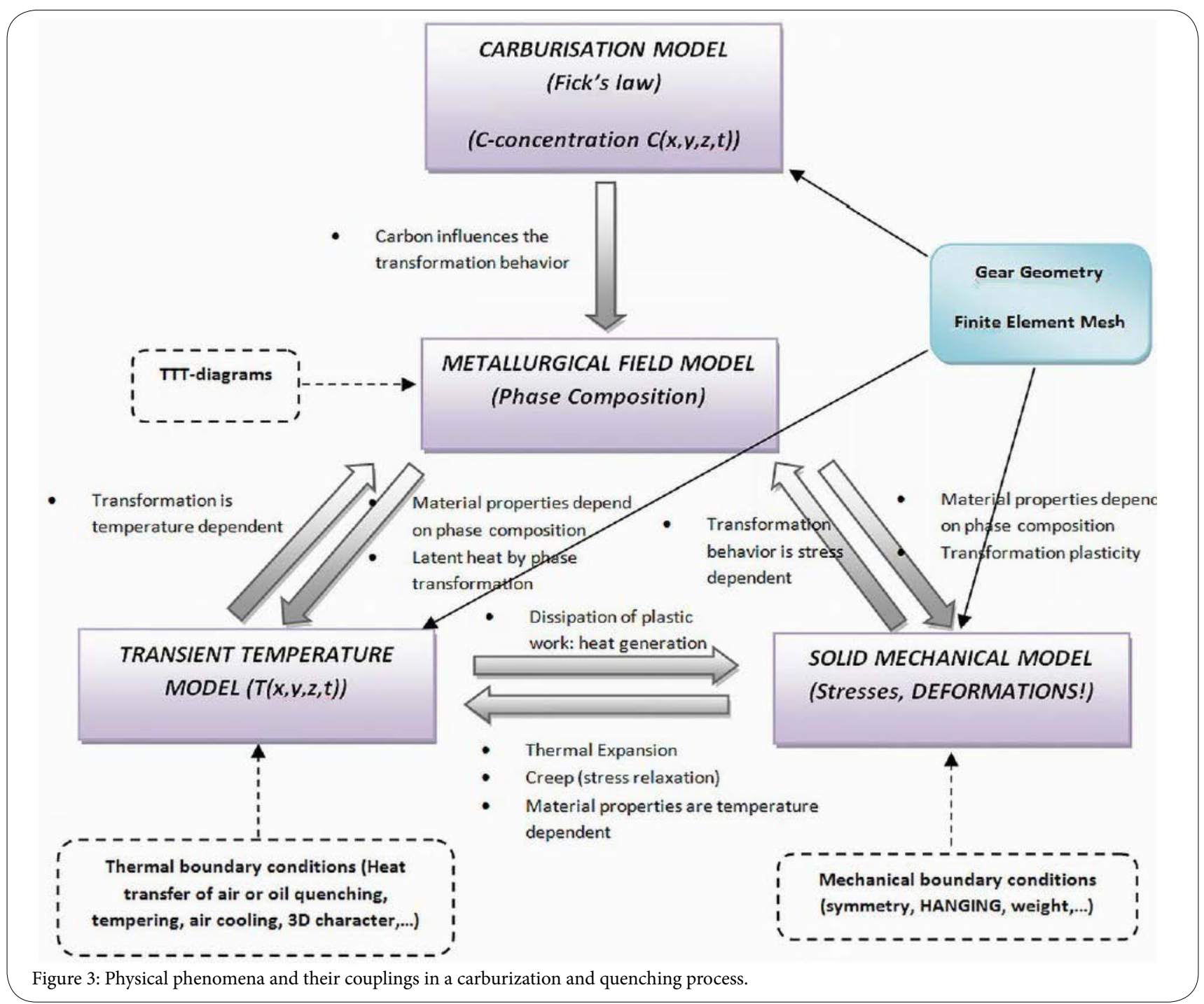


Citation: Decroos K, Seefeldt M (2017) The Effect of Size on the Distortion Behavior After Carburisation and Quenching Processes of Gears. Int J Metall Mater Eng 3: 139. doi: https://doi.org/10.15344/2455-2372/2017/139

Page 4 of 10

\section{Phase transformation model}

When cooling from the austenitic region, austenite can transform into martensite, bainite pearlite, and ferrite, or a combination of those phases, as shown schematically in the Continuous Cooling Transformation (CCT) diagram of Figure 4. For a certain carbon concentration and a given stress state (see Figure 2), the phase transformation behavior can be calculated based on the temperature history.

For diffusion controlled transformations, the time is divided in several discrete time steps and during each time step, the transformation or the incubation to transformation is considered to be isothermal. For the incubation time, Scheil's additivity theorem states that transformation begins when the accumulated ratio of the time interval on the transformation starting time at that temperature from all previous time steps equals 1 [11].

$$
\sum_{j=1}^{n} \frac{\Delta t_{j}}{\tau_{j}}=1
$$

Once the transformation of austenite started, each time step the transformed phase can be calculated by a Johnson-Mehl-AvramiKolmogorov (JMAK) relationship that describes the isothermal evolution of the $\mathrm{i}$-th phase $\mathrm{f}_{\mathrm{i}}$ as a function of the transformation time $t_{j}$ as given in equation 7 [12].

$$
f_{I}=1-\exp \left(-a(T) t_{j}^{b(T)}\right)
$$

For every temperature, the parameters $\mathrm{a}(\mathrm{T})$ and $\mathrm{b}(\mathrm{T})$ can be deducted from the Time Temperature Transformation (TTT) diagram, based on the times $t_{0.01}$ resp. $t_{0.99}$ on which $1 \%$ resp. $99 \%$ of austenite would be transformed when quenching to that temperature followed by holding. Both can be deducted from the TTT diagram. Based on equation 7 , equation 8 gives the expressions for $\mathrm{a}(\mathrm{T})$ and $\mathrm{b}(\mathrm{T})$.

$$
\begin{aligned}
& a(T)=-\frac{\operatorname{In}(1-0.01)}{t_{0.01}^{b}} \\
& b(T)=\frac{\operatorname{In}\left[\frac{\operatorname{In}(1-0.01)}{\operatorname{In}(1-0.99)}\right]}{\operatorname{In} \frac{t_{0.01}}{t_{0.99}}}
\end{aligned}
$$

The transformation time $t$ from expression 7 , can be calculated based on the time step $\Delta \mathrm{t}$, equation 8 , and the transformed phase of the previous time step $f_{I}^{j-1}$.

$$
t_{j}=\Delta t_{j}+\left[-\frac{\operatorname{In}\left(1-f_{I}^{j-1}\right)}{a(T)}\right]^{\frac{1}{b(T)}}
$$

The diffusionless martensitic transformation is described by a Koistinen and Marburger (KM) model that gives the volume fraction of martensite as a function of the temperature [13]

$$
f_{m}=1-\exp \left[-0.011\left(M_{s}-T\right)\right]
$$

The temperature at which the martensitic transformation starts, $M_{s}$, can also be deducted from the TTT diagram. The influence of stress on the transformation behavior (see Figure 3), like for example the martensitic starting temperature $\mathrm{M}_{\mathrm{s}}$, is not considered in this analysis.

Influence of the carbon concentration on the transformation behavior (steels):

Carbon, together with most common alloying elements (except Aluminum and Cobalt), tends to move the TTT-diagram to higher times [10], in other words facilitating the martensitic transformation for the same (fast) cooling rate.

For a given alloy with a certain carbon concentration C, the transformation starting and finishing curves for each phase of the TTT diagram can be interpolated by a 2 nd order polynomial giving the relationship between the logarithm of the time $t$ as a function of the temperature $\mathrm{T}$ given by equation 11 [9]:

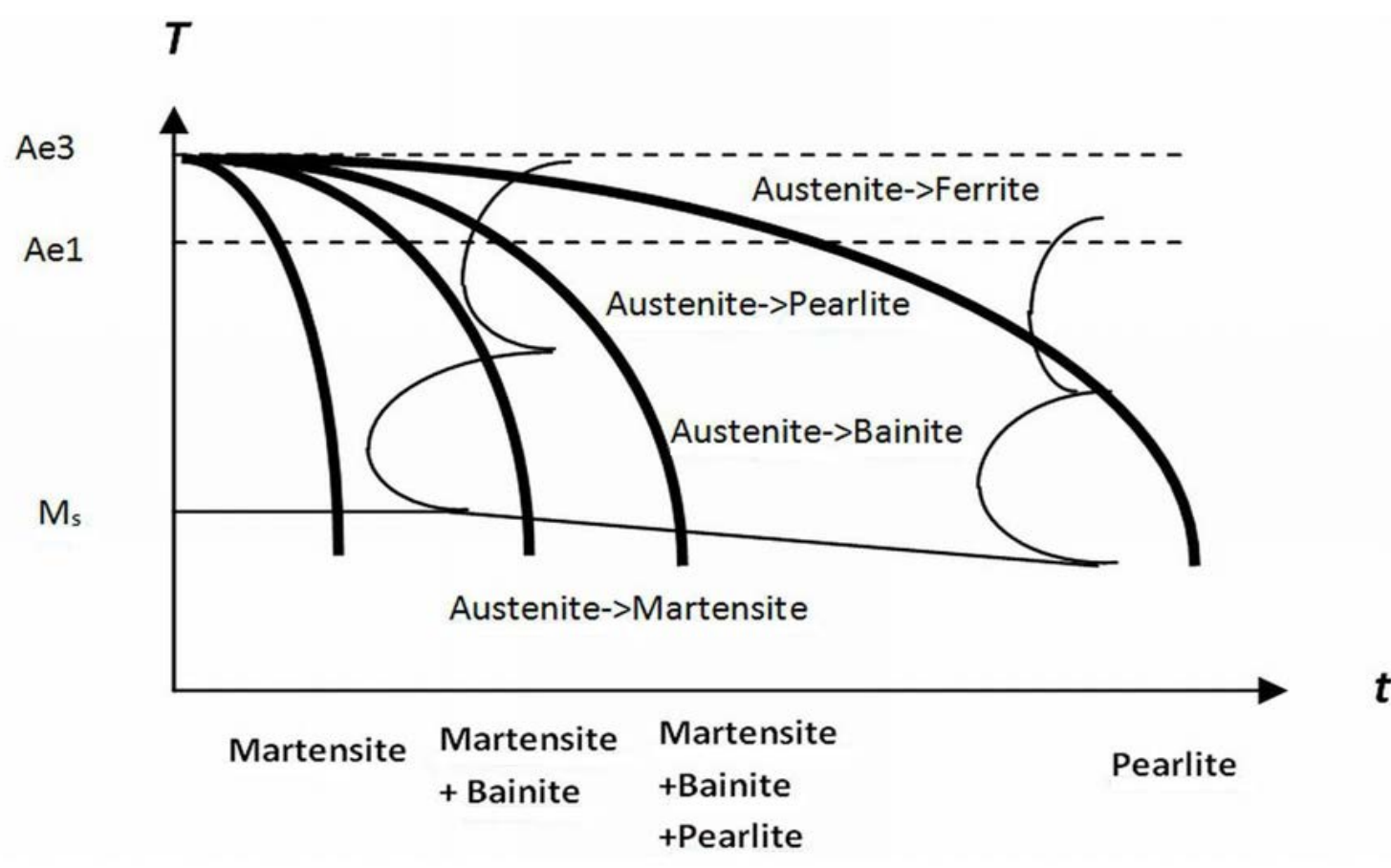

Figure 4: Schematic CCT diagram for austenite decomposition upon cooling. 


$$
\log t=a_{2}(C) T^{2}+a_{1}(C) T+a_{0}(C)
$$

The phase transformation starting curves are found in reference [16] for 2 case hardening steels with the same alloying composition, except for the carbon concentration. The first steel has a carbon weight $\%$ of $0.2 \%$, the second $0.97 \%$, covering the range of concentrations observed in the investigated current work.

For an arbitrary carbon concentration, the coefficients $a_{i}(C)$ for a phase transformation starting curve are interpolated based on the coefficients for these steels and the carbon concentration. Since the output of the diffusion model is the carbon concentration, the procedure allows to obtain an analytical expression for all relevant starting and finishing lines of the TTT-diagram at any point in space.

\section{Mechanical model}

The total strain rate is an additive sum of strain rates [15]: the thermal, elastic, plastic, Transformation Induced Plasticity (TRIP) strain rate, and the phase transformation strain rate.

$$
\dot{\varepsilon}_{e l, i j}=\dot{\varepsilon}_{e l, i j}+\dot{\varepsilon}_{p l, i j}+\dot{\varepsilon}_{t h, i j}+\dot{\varepsilon}_{T F, i j}+\dot{\varepsilon}_{T R, i j}
$$

\section{Thermal strain}

For isotropic materials, the thermal strain is given in equation 13:

$$
\varepsilon_{t h, i j}=\alpha_{s e}\left(T-T_{r e f}\right) \delta_{i j}
$$

with $\alpha_{\text {se }}$ the secant thermal expansion coefficient, $T_{\text {ref }}$ the stress-free reference temperature, $\delta_{\mathrm{ij}}$ the Kronecker delta.

\section{Elastic strain}

The relationship between stress and elastic strain is given by the generalised Hooke's law of equation 14.

$$
\sigma_{i j}=C_{i j k l} \varepsilon_{k l}
$$

The fourth order tensor $\mathrm{C}$ is named the stiffness tensor, and has 2 independent constants in the case of an isotropic material, for example Young's Modulus and Poisson's ratio.

\section{Plastic strain}

Plastic strain rates are related to the plastic potential function [16] by formula 15 .

$$
\dot{\varepsilon}_{i j}=\dot{\lambda} \frac{\partial Q}{\partial \sigma_{i j}}
$$

Hereby $Q$ is the plastic potential function in stress space and equals the yield function when associated plasticity is assumed. $\dot{\lambda}$ is a proportionality constant, forcing the stress to fulfill the yield criterion at all times, when using rate independent plasticity. In this analysis, rate independent associated with a Prandtl-Reuss flow rule with a von Mises Hill criterion [17] and an isotropic work hardening law [5] is used.

\section{Phase transformation strain}

Transformation strain is the strain due to the difference in unit cell dimensions between austenite and the transformed phase [2]. Based on the relative volume change between austenite and the new phase I,
$\frac{\Delta V_{I}}{V}$, the transformation strain rate is given by equation 16

$$
\dot{\varepsilon}_{T F, i j}=\frac{1}{3} \frac{\Delta V_{1}}{V} \dot{f}_{I} \delta_{i j}
$$

\section{Transformation Induced Plasticity (TRIP)}

Transformation induced plastic (TRIP) strain is the irreversible strain, even under low stresses, when a phase transformation occurs [18].

$$
\dot{\varepsilon}_{T R, i j}=K \dot{f}_{I}\left(1-f_{I}\right) s_{i j}
$$

Hereby $f_{I}$ is the transformed fraction, $K$ is a constant, $s_{i j}$ is the deviatoric stress. In reference [9], it is explained how to implement TRIP in a commercial FE software package.

\section{Finite Element modeling}

The geometry in the Finite Element model is constructed based on the mathematical equations of the lines and surfaces, that form the boundaries of the gear's body. The non straight lines are created by means of cubic splines passing through nodes that have been defined based on the parametric expression of the line. The parametric equation of the involute line of the gear tooth of Figure 1, is depending only on the constants $\mathrm{R}_{\text {base }}$. Resizing $\mathrm{R}_{\text {base }}$ with a factor 10 and using the parameter equation will automatically generate the equivalent line in the solid FE model of the lab-scale gear.

The specimen is meshed such that there is a mesh refinement in the direction where the highest gradients are expected. In both the diffusion, thermal, metallurgical and mechanical model, that direction is the normal to the external surface.

Because of symmetry it is sufficient to model only $1 / 48^{\text {th }}$ of the total gear, as shown in Figure 5. The mesh of the real gear and the lab-scale gear consists of 213608 node brick elements and 24764 nodes, and is shown in Figure 5.

Perpendicular to the symmetry plane, which is in the tangential direction, there is a zero tangential carbon flow in the diffusion run, a zero thermal flux in the thermal run, and a zero radial displacement in the mechanical run.

As initial condition in the diffusion run there is a material carbon concentration of $0.19 \mathrm{wt} \%$, in the thermal run the initial temperature is the soaking temperature. As a mechanical initial condition, it is reasonable to accept that the material is completely stress-free just before the quenching process [2]. The metallurgical initial condition is that the metal is initially fully austenitic.

The way to implement phenomena, such as the calculation procedure for the carbon concentration, Transformation Induced Plasticity, and gravity in a commercial Finite Element code has been explained in reference [9].

In $3 \mathrm{D} \mathrm{FE}$ analysis, one commonly assigns a material to a volume of the solid model. Since in a FE solution procedure of any kind one has to calculate integrals over the entire volume [19] with material properties in the integrand, one can state [20]: 
Citation: Decroos K, Seefeldt M (2017) The Effect of Size on the Distortion Behavior After Carburisation and Quenching Processes of Gears. Int J Metall Mater Eng 3: 139. doi: https://doi.org/10.15344/2455-2372/2017/139

Page 6 of 10

$$
\int_{V} \ldots d V=\sum_{\text {elements }} \int_{V_{e}} \ldots d V
$$

because the volume is divided in elements. Therefore, it is possible to define a different material law for every element $[9,20]$. In this analysis, every element's material properties are dependent on the calculated element's carbon concentration, and the element's temperature and temperature history.

Temperature dependent material data for each phase are taken from reference [21]. A rule of mixture is used to calculate the properties based on the phase fractions.

\section{Results and Discussion}

The results of the diffusion model are the carbon concentrations in the specimen after the carburisation and soaking process. The results of the thermal run are the temperatures at every point in space starting from the soaking process, followed by quenching, tempering, and air cooling. The mechanical model calculates strains, stresses, and displacements after these processes. The results for both geometries are presented by means of line plots for the lines schematically shown in Figure 6.

\section{Carbon concentration}

The carbon concentration after the diffusion process for both geometries is shown in Figure 7.

Both curves have a Gaussian shape with a comparable width at half maximum, and a comparable maximal value. The maximal carbon concentration at the outside surface is $0.83 \mathrm{wt} \%$ in the case of the realtime geometry, and $0.76 \mathrm{wt} \%$ in the case of the test geometry. The distance from the outer surface at which the carbon concentration is half of its maximal value is $1.4 \mathrm{~mm}$ for the real time case, and $1.35 \mathrm{~mm}$ for the test sample..In both cases, at $3 \mathrm{~mm}$ the concentration is the same of the initial bulk concentration of $0.19 \mathrm{wt} \%$.

When considering the different length scales in mesh divisions, the small component has a ten times finer mesh than the large component. The similar results in both magnitude and shape for the final carbon concentration in the 2 specimens show that the prediction of the carbon concentration is not sensitive to the mesh density. The latter is thought to be due to the long times and the monotonous character of the carbon diffusion problem in the case of carburizing.

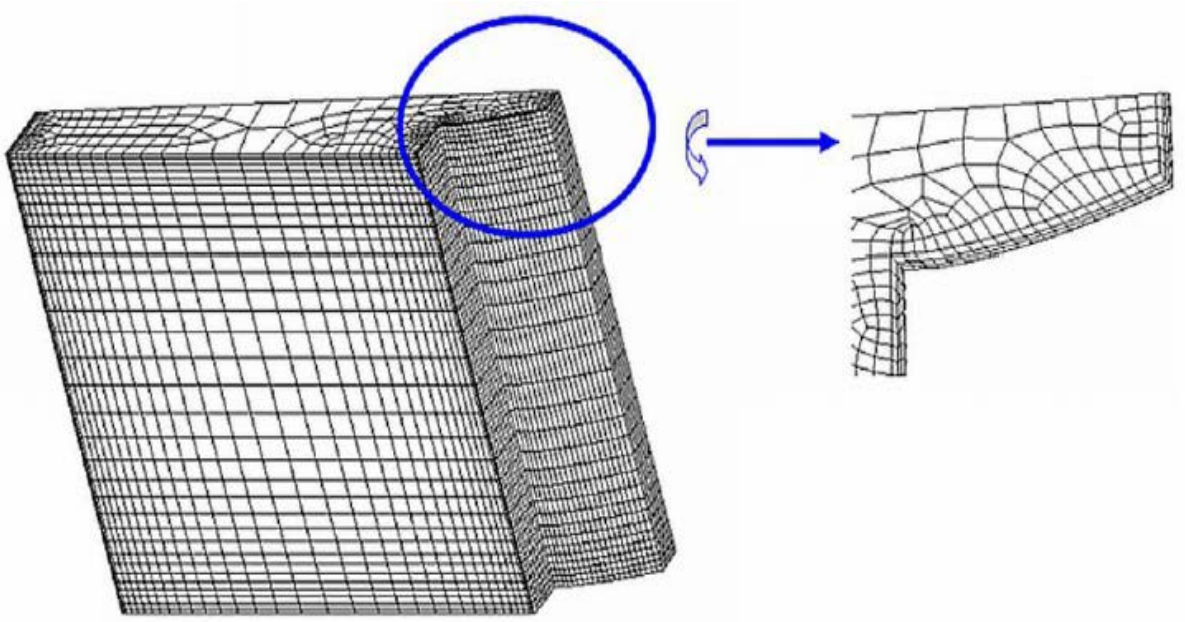

Figure 5: FE mesh off the gear used for both the large gear as the lab-scale gear.

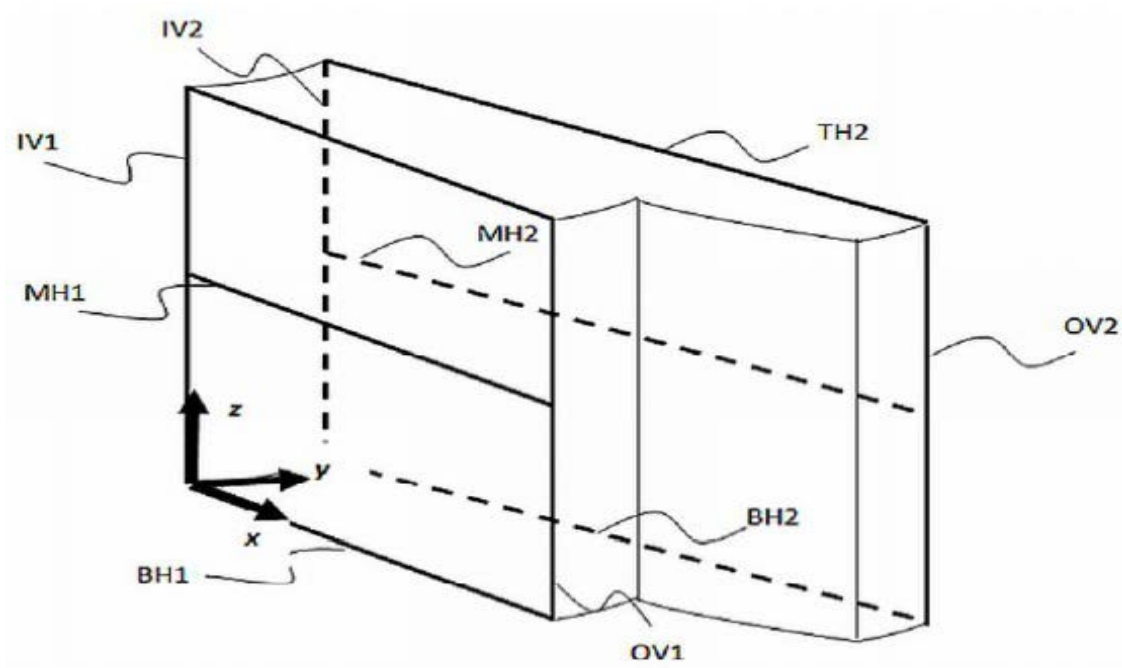

Figure 6: Schematic sketch of the gear. Several lines are shown that are used for line plots. 
Citation: Decroos K, Seefeldt M (2017) The Effect of Size on the Distortion Behavior After Carburisation and Quenching Processes of Gears. Int J Metall Mater Eng 3: 139. doi: https://doi.org/10.15344/2455-2372/2017/139

Page 7 of 10

\section{Phase composition}

The martensite fraction after diffusion and rapid cooling for both geometries is shown in Figure 8.
In the real-time geometry, the martensite volume fraction curve has a Gaussian shape, with a maximal martensite fraction at the surface of $92.6 \%$. The fraction drops to zero at approximately $3.2 \mathrm{~mm}$ depth. The martensite curve of the test geometry is completely different. That is due to the size effect which causes a more rapid cooling than in the
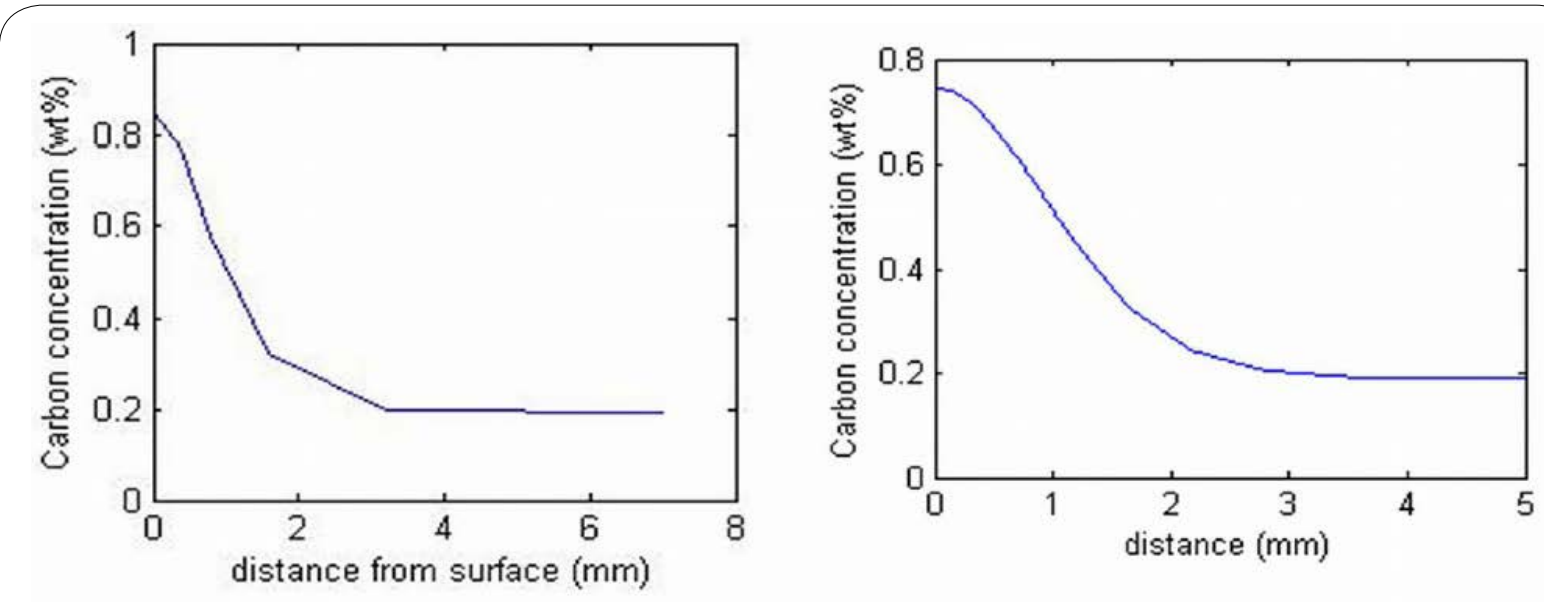

a

b

Figure 7: Carbon concentration on line MH2, starting from the outside surface. a) real gear. b) lab-scaled gear.

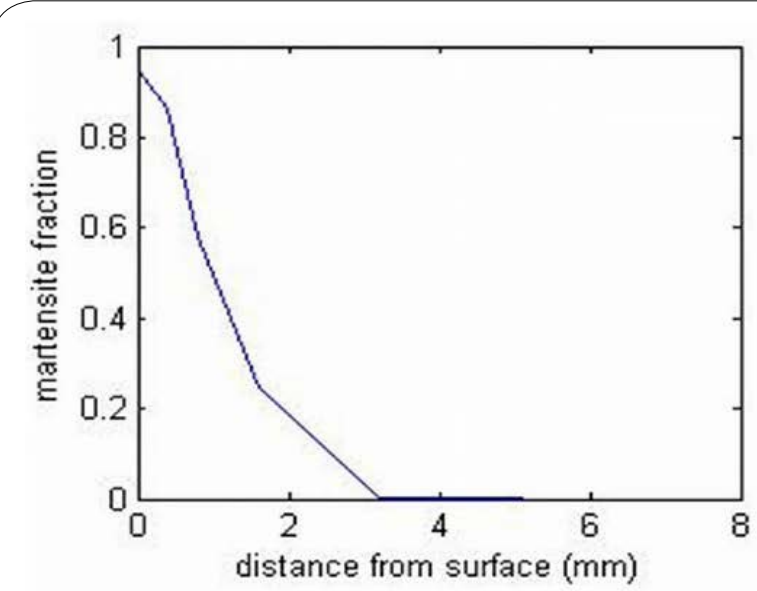

a

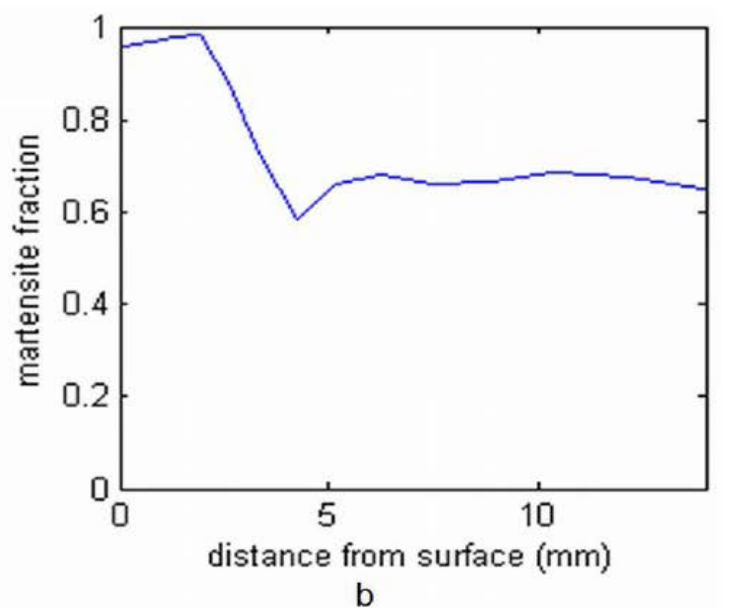

$b$

Figure 8: Martensite volume fraction on line $\mathrm{MH}$ 2, starting from the outside surface. a) real gear. b) lab-scaled gear.

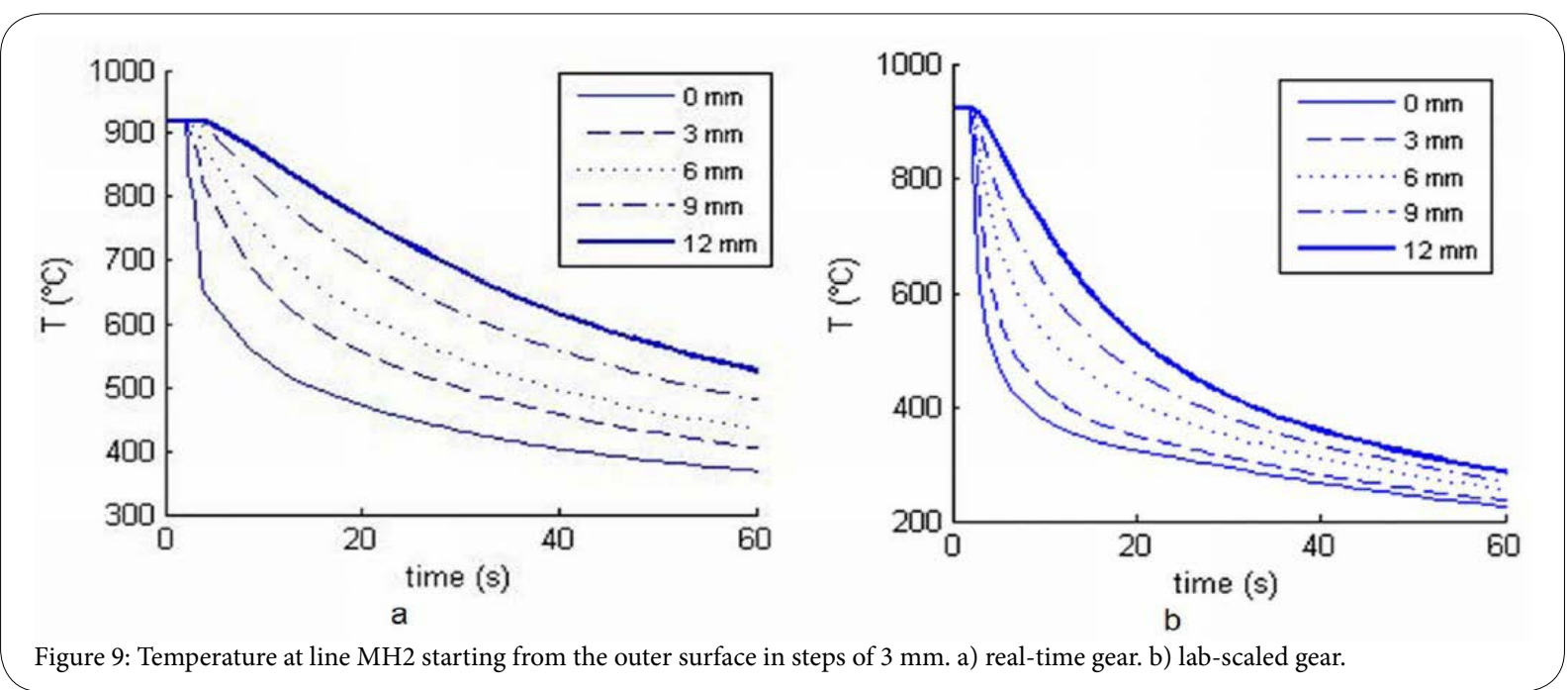


Citation: Decroos K, Seefeldt M (2017) The Effect of Size on the Distortion Behavior After Carburisation and Quenching Processes of Gears. Int J Metall Mater Eng 3: 139. doi: https://doi.org/10.15344/2455-2372/2017/139

Page 8 of 10

large geometry case. The martensite fraction at the surface is $93.5 \%$ and eventually drops to approximately $65 \%$ at $4.5 \mathrm{~mm}$. Note that for the test component the range of the graph of Figure $6 \mathrm{~b}$, namely $15 \mathrm{~mm}$, is half of the size of the test component. The reason for the fluctuations in the curve is thought to be computational rather than physical.

\section{Temperature}

The temperature histories until 1 minute at several points of line MH2 (see Figure 5) are shown in Figure 9.

After 1 minute, the temperature difference between the surface and a point at $12 \mathrm{~mm}$ from the surface is approximately $180{ }^{\circ} \mathrm{C}$ for the large component, and $60^{\circ} \mathrm{C}$ for the small component. At $12 \mathrm{~mm}$ depth, in the first case the temperature after 1 minute drops to 550 ${ }^{\circ} \mathrm{C}$, and in the second case $300{ }^{\circ} \mathrm{C}$. The latter is already beneath the martensite starting temperature of $415^{\circ} \mathrm{C}$ for a carbon concentration of $0.19 \mathrm{wt} \%$, which explains the martensite fraction of approximately $65 \%$ at that point, see Figure $9 \mathrm{~b}$.

\section{Deformation/distortion/residual stress}

The mechanical model predicts stresses, strains, and displacements after the quenching process. In the current work, the initial shape before the process is the same as the desired afterwards, which means the displacements of the surface can be considered as distortions.

The tangential residual stresses for both models on the 2 radial lines MH1 and MH2 (Figure 6) are shown in Figure 10.

For both models, except for the scaled ordinate axis, the stress curves have a similar shape and magnitude. The residual tangential stress is compressive at the outer surface of about $400 \mathrm{MPa}$, and has a higher tensile stress in the middle tending towards $600 \mathrm{MPa}$.

The tangential stresses on line MH2 are shown in Figure 11.

In both cases show again a very similar stress curve. Due to the gear tooth which lies along the line $\mathrm{MH} 2$, the profile is different from line

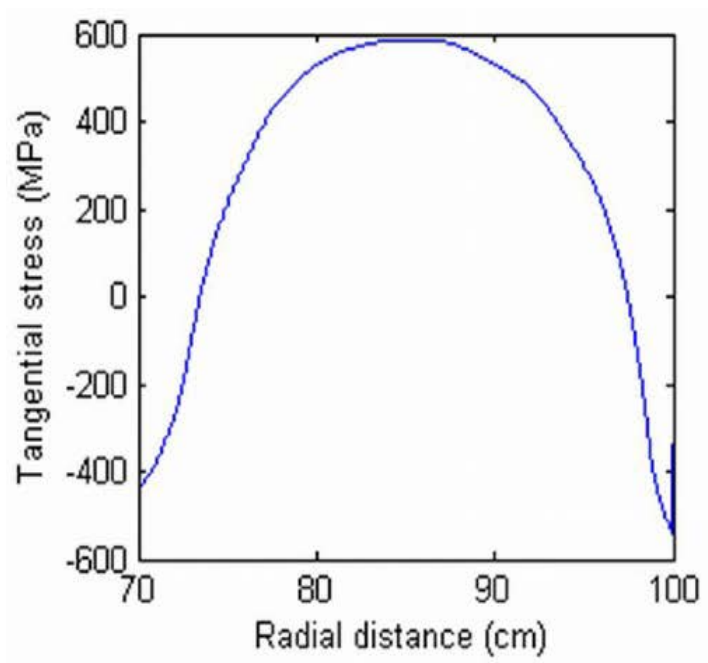

a

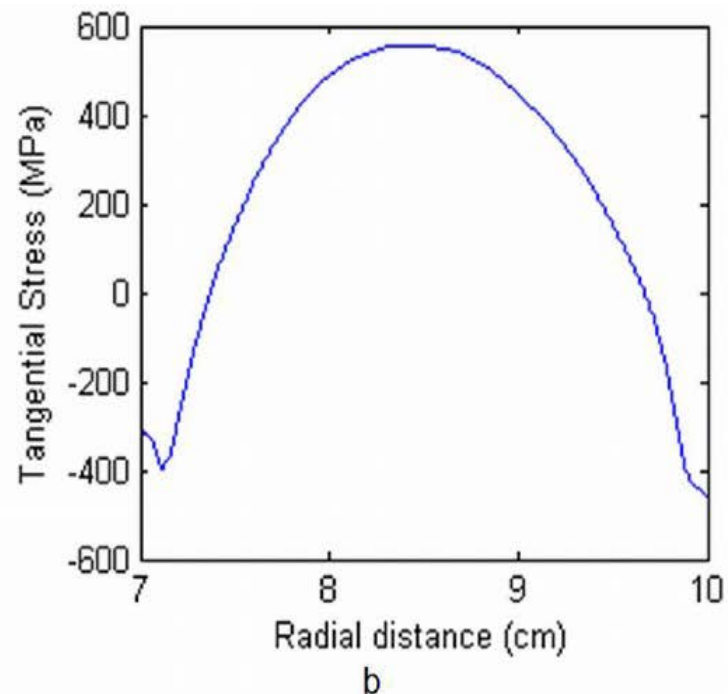

Figure 10: Residual tangential stresses for the 2 mechanical models on line MH1. a) real-time gear. b) lab-scaled gear.

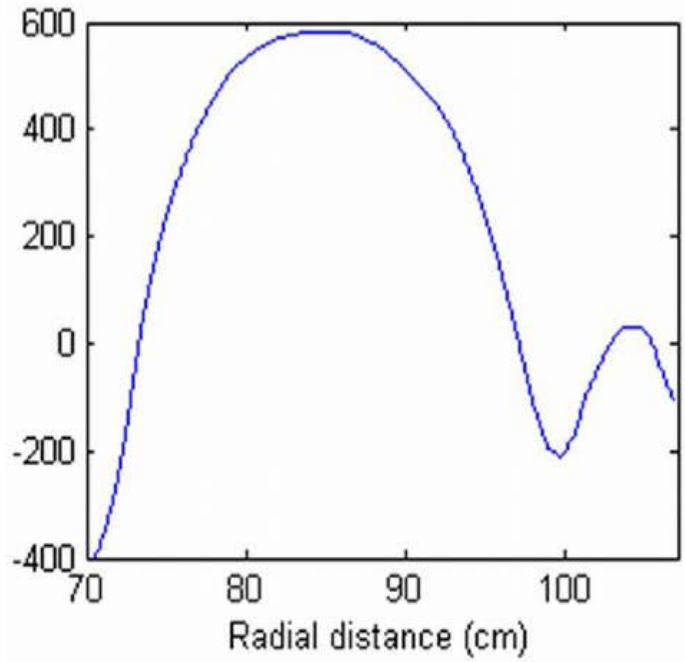

a

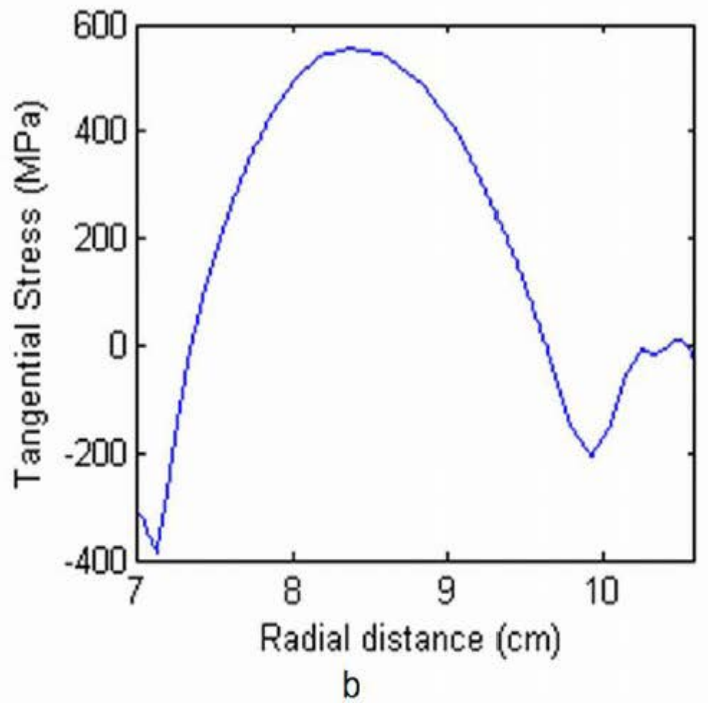

b

Figure 11: Residual tangential stresses for the 2 mechanical models on line MH2. a) real-time gear. b) lab-scaled gear. 
Citation: Decroos K, Seefeldt M (2017) The Effect of Size on the Distortion Behavior After Carburisation and Quenching Processes of Gears. Int J Metall Mater Eng 3: 139. doi: https://doi.org/10.15344/2455-2372/2017/139

Page 9 of 10
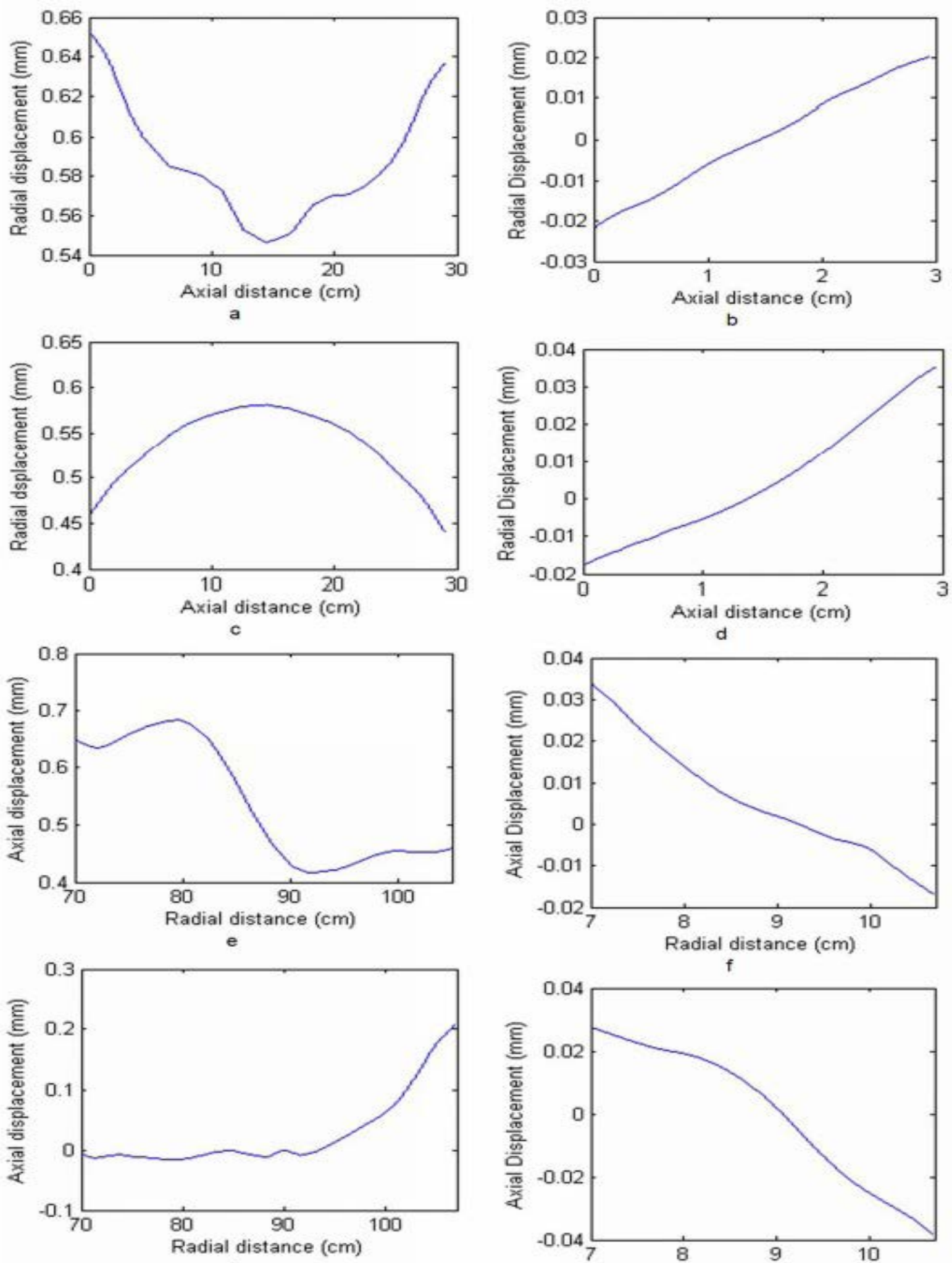

g
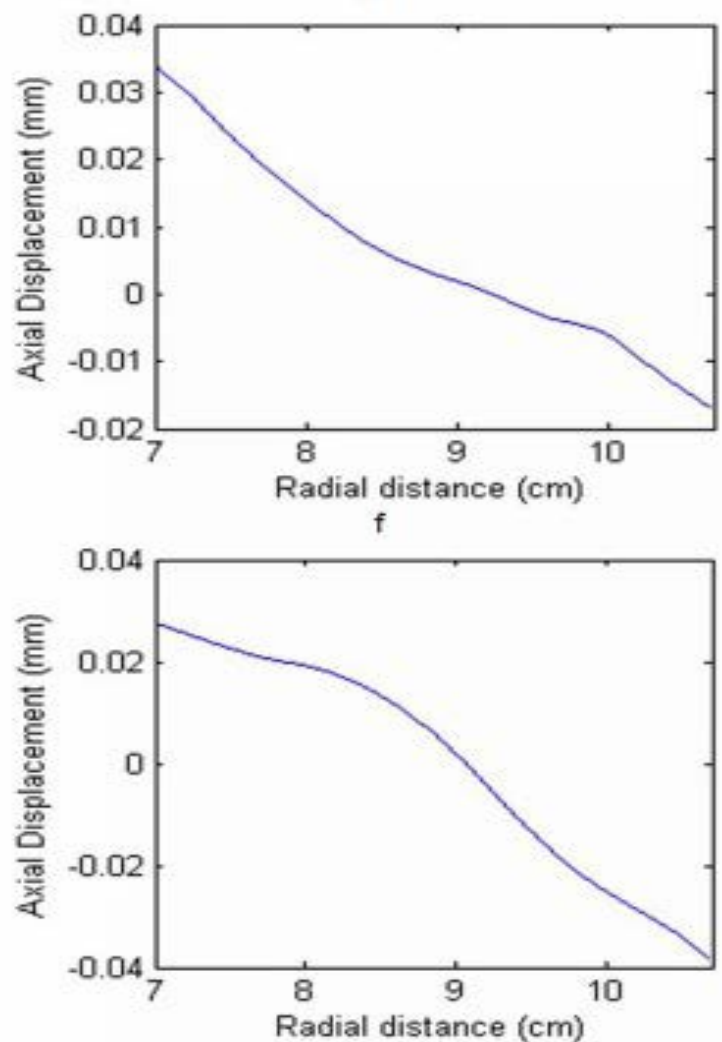

h

Figure 12: Displacements along vertical and horizontal lines. On the left-hand side plots are shown for the real gear, on the right-hand side for the lab-scale gear. a) and b) Radial displacement along line IV2 (inside). c) and d) Radial displacements along line OV2 (outside). e) and f) Axial displacement along line BH2. (bottom). g) and h) Axial displacement along line TH2 (top). 
Citation: Decroos K, Seefeldt M (2017) The Effect of Size on the Distortion Behavior After Carburisation and Quenching Processes of Gears. Int J Metall Mater Eng 3: 139. doi: https://doi.org/10.15344/2455-2372/2017/139

Page 10 of 10

MH1, see Figure 10. Away from the tooth (left of the curve), the same compressive stresses as on line $\mathrm{MH} 1$ are found, and more towards the centre, one has tensile stresses almost reaching $600 \mathrm{MPa}$.

The calculated displacements along certain lines (Figure 6) are shown in Figure 12.

The larger component shows displacements in the order of tenths of $\mathrm{mm}$, with maximum $0.7 \mathrm{~mm}$, see Figure 12e. The small component shows displacements in the orders of hundreds of $\mathrm{mm}$, with a maximum of $0.035 \mathrm{~mm}$ (Figure 12d).

The large model predict that a radial-axial cross section of the gear will have a barrel-type of deformation after carburization and quenching. The top and the bottom surface have a more complex deformation, as can be seen in Figure $12 \mathrm{c}$ and 12d. Again there is a clear difference in distortion prediction between the 2 models, with a difference reaching $1 \mathrm{~mm}$. in the small case, since the outer vertical and horizontal radial respectively axial displacements follow more or less exactly the same tendency, the gear is rather rotated than deformed as a consequence of the quenching process. In general, the modeled deformations along the vertical lines show a good agreement with the experimental observations of a quenched hollow cylinder with similar inner and outer diameter to height ratio [22] for the large case, but not for the small case. This might be due to the fact that the martensite phase, which has a higher unit volume, see equation 16 has lower gradients throughout the specimen (Figure 12b).

\section{Conclusions}

A three-dimensional model to predict carbon concentrations, thermal histories, phase compositions, stresses, strains and displacements after a carburization and quenching process of gears has been used to investigate the differences between a large component gear, and a gear with exactly the same shape, but with length scales of a factor 10 smaller. Both specimens have undergone the same temperature cycle. The physical couplings have been incorporated in a diffusion FE model that models the carburization and soaking process, followed by a thermo-metallo-mechanical FE model that models the quenching process. Effects that become important when the size of the quenched components increase, namely gravity and immersion time, have been taken into account in both cases.

The results of the diffusional models show a similar carbon concentration profile and magnitude for the large component and the test component. As both FE meshes consist of a similar number of elements, and considering that the difference in length scales, it can be concluded that the carbon concentration calculations in carburization and soaking processes are mesh insensitive.

The thermal results show, as expected, faster cooling rates for the lab-scale specimen than for the large component gear. The implications for the metallurgical transformations are such that the nose of the bainite transformation is avoided, and martensite forms through the entire lab-scale specimen, whereas the martensite penetration is in the order of millimeters in the large component gear.

The quenching stresses, which are the causes of the deformations, show a very similar magnitude and profile for the large component and the lab-scale component when scaling the length coordinate. However, the deformations are of a completely different nature. From this study it can been concluded that the deformation behavior after carburisation and quenching of a lab-scale component can not be extrapolated to a larger scaled component when the length scales are of a different order. However, the residual stress profiles are independent of the component's size.

\section{Conflict of Intrests}

Authors declare no Conflict of Interests for this article.

\section{References}

1. Davis JR (2005) Gear Materials, Properties, and Manufacture. ASM International.

2. Lapman S (1990) Introduction to Surface hardening of Steels. In: ASM (Ed.), ASM Metals HandBook Vol. 4: heat treating.

3. Pan J (2002) Factors Affecting Final Part Shaping. In: M. Howes, T. Inoue, G. Totten (Eds.), Handbook of Residual Stress and Deformation of Steel, ASM International.

4. Nallathambi AK, Kaymak Y, Specht E, Bertram A (2010) Sensitivity of material properties on distortion and residual stresses during metal quenching processes. J Mat Proc Tech 210: 204-211.

5. ANSYS (2008) ANSYS 11.0 Complete User's Manual Set.

6. Kang SH, Im YT (2007) Three-dimensional thermo-elastic-plastic finite element modeling of quenching process of plain-carbon steel in couple with phase transformation. Int J Mech Sc 49: 423-439.

7. Huiping L, Guoqun Z, Shanting N, Chuanzhen H (2007) FEM simulation of quenching process and experimental verification of simulation results. Mat ScEng A 452-453: 705-714.

8. Sugianto A, Narazaki M, Kogawara M, Shirayori A, Kim SY, et al. (2009) Numerical simulation and experimental verification of carburizingquenching process of SCr420H steel helical gear. J Mat Proc 209: 35973609.

9. Decroos K, Seefeldt M (2013) Modelling of distortions after carburisation and quenching processes of large gears, submitted to Model. Simul Mater Sci Eng 21: 3.

10. HKDH, Bhadeshia R, Honeycombe (2003) Steels, Microstructure and Properties, Oxford, Elsevier.

11. Scheil E (1935) Anlaufzeit der Ausenitumwandlung. Arch Eisenh 12: 564 567.

12. Avrami M (1939) Kinetics of phase change i-iii. J Chem Phys 7: 1103-1112.

13. Koistinen DP, Marburger RE (1959) A gerneral equation prescribing the extend of the austenite-martensite transformation in pure iron-carbon alloys and plane carbon steels. Acta Met 7: 59-60.

14. Popova LE, Popov AA (1991) Diagrams of transformation of austenite in steels and beta solution in Titanium. Moscow, Metallurgiya.

15. Lindgren LE (2006) Numerical modelling of welding. Comp Meth Appl Mech Engrg 195: 6710-6736.

16. Houtte PV (1994) Application of plastic potentials to strain rate sensitive and insensitive anisotropic materials. Int $\mathrm{J}$ of Plast 10: 719-748.

17. Mises RV (1928) Mechanik der Plastischen Formänderung der Kristallen. Z angew Math Mech 8: 161-185.

18. Greenwood GW, Johnson RH (1965) The deformation of metals under small stress during phase transformation. Proc Royal Sc A 283: 403-422.

19. Zienkiewitz OC, Taylor RL (2000) The Finite Element Method Vol. 2 Solid Mechanics. Butterworth-Heinemann.

20. Decroos K, Ohms C, Houbaert Y (2008) Ceramics Transactions. 200: 115123.

21. Alberg H, Berglund D (2003) Comparison of Plastic, Viscoplastic, and Creep Models when Modelling Welding and Stress Relief Heat Treatment. Comp Meth App Mech Eng 192: 5189-5208.

22. M. Narazaki, In: M. Howes, T. Inoue, G. Totten, (Eds.), Handbook of Residual Stress and Deformation of Steel, ASM International, 2002, pp. 248-295. 